\title{
Almost Everything Is Relative in the Caucasus
}

\author{
Ivano Caponigro \\ University of California, San Diego
}

\author{
Maria Polinsky \\ Harvard University
}

\section{Caucasian puzzles}

Embedded clauses have many forms and meanings. In particular, relative clauses, embedded declaratives, and embedded interrogative clauses are assigned very different interpretations, despite their common clausal nature. A headed relative like which Adam cooked is standardly assumed to denote the set of individuals that Adam cooked (Quine 1960; Montague 1973); a free relative like what Adam cooked denotes the (plural) individual that Adam cooked (Jacobson 1995, Caponigro 2004); an embedded declarative like that Adam cooked vegetables denotes the proposition 'that Adam cooked vegetables'; an embedded polar interrogative like whether Adam cooked vegetables denotes a set containing the proposition 'that Adam cooked vegetables' and/or its negation 'that Adam did not cook vegetables'; finally, an embedded constituent interrogative like which food Adam cooked denotes the set of propositions that are (true) answers to the question 'which food did Adam cook?' (see Hamblin 1973 and Karttunen 1977 for the semantics of both types of interrogatives). These differences in meaning correspond to differences in the morphosyntax: the presence or absence of a wh-word, relative pronoun, or overt complementizer; syntactic transparency (embedded declaratives) or syntactic opacity (relatives and interrogatives); and differences in the nature of the complementizer (Rizzi 1990: ch. 2).

While we are used to this pattern in familiar languages, our theories of grammar do not require it to be the only one possible or necessary. In this paper, we present and analyze new empirical evidence suggesting that it actually is not the only pattern found across languages. The evidence comes from Adyghe, a Northwest Caucasian language, which behaves very differently as far as clausal subordination is concerned. What looks like the same construction (for now we will refer to it as the "mystery clause", MC) is used to convey the five different meanings above. This raises two questions: (i) what kind of construction the MC

This work was supported in part by the NSF grant BCS-0131993 and a grant from the Davis Center for Russian and Eurasian Studies at Harvard to the second author. We are grateful to our language consultants Raxmet Esheva, Raxmet Gisheva, Svetlana Kinokova, Mira Unarokova, and Acherdan Abzhegov. We would like to thank R. Bhatt, G. Chierchia, D. Gerasimov, A. Giannakidou, C. Kennedy, S.-S.Kim, Y. Lander, A. Letuchiy, E. Potsdam, Y. Testelets, and the audiences at WCCFL 27, GLOW 31, and SALT XVIII for helpful comments on this paper. Standard disclaimers apply. 
is, and (ii) how the same construction is mapped into meanings as different as individuals, sets of individuals, propositions, and sets of propositions. We address puzzle (i) in Caponigro and Polinsky (to appear), where we argue that MCs are invariably complex DPs containing a relative clause. In this paper, we focus on puzzle (ii): how can a complex DP containing a relative clause be mapped into five different meanings? Section 2 of the paper gives a brief background on Adyghe. Section 3 develops our proposal about the syntax/semantics interface of MCs. Section 4 presents our conclusions.

\section{A brief introduction to Adyghe}

Adyghe (ady; also known as West Circassian), spoken by about 150,000 people in the south of Russia, is a morphologically rich language with an absolutive/ergative case system (syncretic for first and second person). Nouns are inflected for what we will refer to as "specificity" (currently, it is unclear to us what the precise semantic import of case marking is). Specific DPs have overt marking both in the ergative (ERG) and absolutive (ABS), as shown in (1). Non-specific forms of both cases have zero marking, as shown in (2). ${ }^{1}$ Other cases include the generalized oblique $(-m)$ and instrumental $-\check{c}$ ' $e$, always overtly marked.
ç̣’ale-m mə mašine-r Ø-ə- $\mathrm{q}_{\mathrm{w}}$ əta-ь
boy-ERG this car-ABS 3SG.ABS-3SG.ERG-break-PAST.DECL
'The boy broke this car.'
ç̣’ale-xe- $\varnothing$ mašine- $\varnothing$ Ø-a-q $\mathrm{q}_{\mathrm{w}}$ əta
boy-PL-ERG car-ABS 3PL.ABS-3PL.ERG-break.PRES.DECL
'Boys break cars.'

Verbal morphology is particularly complex. A verb can agree in person/number with subject, object, and indirect object (cf. Colarusso 1992: 74, 132-135; O'Herin 2002: 49-69 for agreement in the closely related Kabardian and Abaza respectively) and has separate positional slots for negation, tense, aspect, causation, mood, and illocutionary force (Smeets 1984: Ch. 5, 6; Rogava and Keraševa 1966: 95-331). In addition, Adyghe has a rich system of applicative heads (traditionally referred to as preverbs, see Smeets 1984: 256-67) that incorporate into the verbal complex and serve as hosts for the agreement marker indexing their complement (see O’Herin 2001 for similar applicatives in Abaza). The scarcity of postpositions may be a trade-off of this articulated applicative system; most of the phrases corresponding to PPs in other languages have to be

\footnotetext{
${ }^{1} 3$ rd person absolutive has a null agreement marker, which will be omitted from the glosses beyond (1) through (3).
} 
expressed by a dedicated applicative in the verb and its complement in the oblique case which is indexed by agreement on the relevant head, as shown in (3).

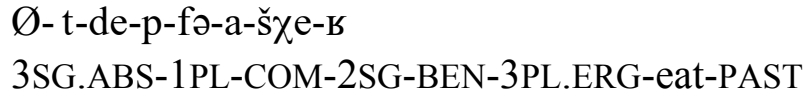

'They ate this with us for you.'

Word order in root clauses is extremely free (for instance, in matrix declarative clauses such as (1), all six word orders are possible); however, embedded clauses must be verb-final. The language has extensive subject and object pro-drop.

\section{The syntax/semantics of Adyghe mystery clauses}

In Caponigro and Polinsky (to appear), we show that all Adyghe MCs have the same basic morphosyntactic structure: they are all complex DPs with a relative clause inside, thus they instantiate a syntactic configuration in which an operator binds an empty category. On the other hand, MCs receive five different interpretations, according to the agreement morphology on the verb and/or the environment they occur in. In this section, we address the puzzle of how the same morphosyntactic structure can be mapped into five different meanings. For each meaning, we first briefly introduce the MC that conveys that meaning, then highlight the main aspects of its syntactic and semantic analysis to show how its meaning is compositionally derived, and finally give the syntactic tree and the logical translation of an example.

\section{1. "Headed relative" interpretation}

Example (4) shows an MC that behaves like a headed relative clause: it directly precedes the noun ç'ale 'boy' (the head of the relative clause), restricts the meaning of the noun to the set containing just the boy who broke a contextually salient car, and together with the noun forms the bracketed complex DP.

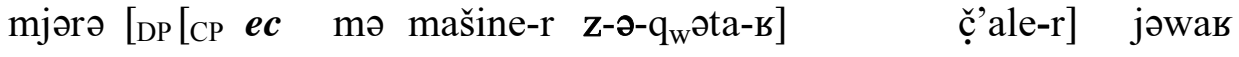

$$
\begin{aligned}
& \text { Mira this car-ABS WH-ERG-break-PAST boy-ABS beat }
\end{aligned}
$$

If we compare (4) with the declarative clause in (1) above, two main differences stand out. In the declarative clause in (1), the noun ç'ale 'boy' precedes the verb 'broke', receives the ergative case $(-m)$ from the verb, and acts as the subject. The bracketed MC in (4), instead, has a gap in subject position, which we indicate with an empty category $(e c)$. Notice that the MC shows the same ergative subject 
agreement prefix $-\curvearrowright$ as in the matrix declarative in (1). On the other hand, the nominal čcale 'boy' now occurs after the MC verb and its case (absolutive) is determined by the matrix verb 'beat', rather than by the MC verb 'broke.' This is an expected pattern for a noun and its modifying relative clause in a head-final language like Adyghe.

The second difference has to do with additional verbal morphology. The verb in the MC in (4) has an extra prefix $z$-. We analyze this as a marker of whagreement (glossed as $W H$ ), indicating that there is an operator-variable chain in that clause (see O'Herin 2002: Ch. 8 for a similar analysis of wh-agreement in the related Abaza, and Caponigro and Polinsky to appear for details on Adyghe wh-agreement).

If the extracted argument is in the absolutive position, wh-agreement is signaled by a null marker $(\varnothing)$, as shown in (5). Recall that the absolutive agreement marker is always null, not just in MCs (see the declarative in (1), for instance). ${ }^{2}$

$$
\begin{aligned}
& \text { [DP [CP } \\
& \text { boy-ERG WH.ABS-3SG.ERG-break-PAST car-ABS }
\end{aligned}
$$

'the car that the boy broke'

All other constituents can relativize only if they are introduced as arguments of applicative heads incorporated in the verbal complex (see O'Herin 2001 for applicatives in Abaza). For example, in (6a) the locative expression is an adjunct and is not cross-referenced on the verb, in (6b) the locative applicative is incorporated in the verb and includes an agreement marker indexing 'garden,' and (6c) shows the relativization of the locative argument based on (6b), with the wh-marker preceding the applicative head.

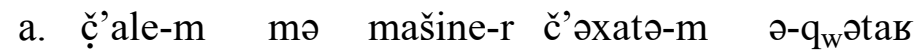
boy-ERG this car-ABS garden-OBL 3SG.ERG-broke 'The boy broke this car in the garden.'

b. č̣’ale-m mə mašine-r č’’xatə-m š̀-jə-q $\mathrm{q}_{\mathrm{w}}$ ətas boy-ERG this car-ABS garden-OBL LOC.3SG-3SG.ERG-broke 'The boy broke this car in the garden.'

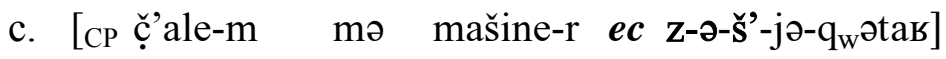 boy-ERG this car-ABS WH-OBL-LOC.3SG-3SG.ERG-broke č’xatə-r garden- ABS 'the garden where boy broke this car'

\footnotetext{
${ }^{2}$ In some dialects of Adyghe and in some related languages, the absolutive wh-agreement marker is not null (Smeets 1984: ch. 5; Colarusso 1992; O’Herin 2002: ch. 8).
} 
We assume that the gap (ec) in an MC like (4), (5), (6c) translates into a variable ranging over individuals and that the operator that binds the variable triggers lambda-abstraction over it. So, the whole MC ends up denoting a set of individuals, which is the standard denotation of a restrictive relative clause. The operator/lambda abstractor $\left(\mathrm{WH}_{1}\right)$ and the gap/variable $\left(\mathrm{x}_{1}\right)$ are licensed by the verbal morphology. In particular, in (4) the WH-agreement prefix (z-) signals the operator-gap configuration, while the person agreement prefix (in some cases in conjunction with the applicative prefix) signals that the variable which the gap (ec) translates into ranges over individuals. The set of individuals the MC denotes combines with the set of individuals the nominal head denotes by standard predicate modification (Quine 1960; Montague 1973). The resulting set is turned into its maximal individual by a maximalization operation. This operation can be implemented by means of a type-shifting rule in the semantics or a silent maximality operator $\delta$ in the syntactic structure. We choose the latter and assume the operator $\delta$ to be the D head of the complex DP that contains the MC. ${ }^{3}$

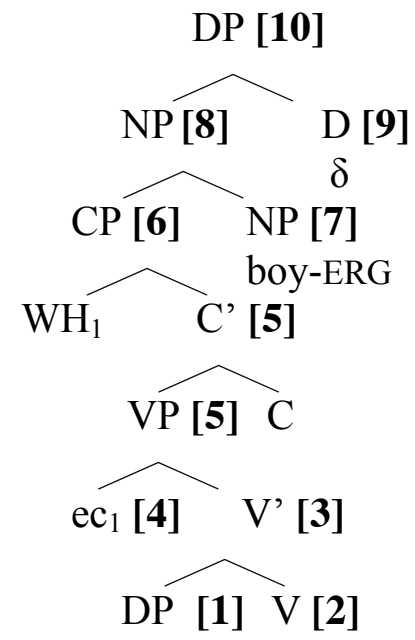

this car-ABS WH-ERG-break-PAST

[1]. [DP this car.ABS] $>\mathrm{c}_{<\mathrm{e}>}$ (constant)

[2]. [v WH.ERG-break-PAST] $>\lambda y . \lambda x \cdot \operatorname{break}(\mathrm{y})(\mathrm{x})$

[3]. $\quad \mathrm{V}^{\prime} \sim>\lambda \mathrm{x} \cdot \operatorname{break}(\mathrm{c})(\mathrm{x})$

[4]. $\quad \mathrm{ec}_{1} \sim>\mathrm{x}_{1<\mathrm{e}>}($ variable $)$

[5]. $\quad \mathrm{VP} \sim \lambda \mathrm{x} .[\operatorname{break}(\mathrm{c})(\mathrm{x})]\left(\mathrm{x}_{1}\right)=\operatorname{break}(\mathrm{c})\left(\mathrm{x}_{1}\right)$

[6]. $\quad\left[\mathrm{CP}_{\mathrm{P}} \mathrm{WH}_{1} \mathrm{C}^{\prime}\right] \sim>\lambda_{\mathrm{x}} \cdot \operatorname{break}(\mathrm{c})\left(\mathrm{x}_{1}\right) \quad$ (Lambda Abstraction)

[7]. $\quad \mathrm{NP} \sim>\lambda \mathrm{x} . \operatorname{boy}(\mathrm{x})$

[8]. $\quad \mathrm{NP} \sim>\lambda \mathrm{x}$.[break $(\mathrm{c})(\mathrm{x}) \wedge \operatorname{boy}(\mathrm{x})] \quad$ (Predicate Modification)

[9]. $\delta \sim>\lambda \mathrm{Q}[\mathrm{ly}[\mathrm{Q}(\mathrm{y})]]$ (Maximalization)

[10]. DP $>\lambda \mathrm{Q}[\mathrm{ly}[\mathrm{Q}(\mathrm{y})]](\lambda \mathrm{x} .[\operatorname{break}(\mathrm{c})(\mathrm{x}) \wedge \operatorname{boy}(\mathrm{x})])=$ $\operatorname{ty}[\operatorname{break}(\mathrm{c})(\mathrm{y}) \wedge \operatorname{boy}(\mathrm{y})]$

\footnotetext{
${ }^{3}$ See Partee (1986), Chierchia (1998), and Dayal (2004) for arguments in favor of this operation with certain NPs/DPs.
} 
(7) above gives the syntactic structure and the semantic derivation of the MC in (4). For the sake of simplicity, we omit the TP projection and various applicative projections between the $\mathrm{CP}$ and the VP in all our trees, unless necessary.

\section{2. "Free relative" interpretation}

An MC can also occur as the argument of a predicate selecting for an individual denoting expression. In (8), for instance, an MC occurs as the complement of the predicate 'beat' and is interpreted as denoting the individual(s) who broke a certain car. This is similar to the semantic behavior of a free relative like who you choose in I'll kiss who you choose in English, which denotes the individual(s) who you choose.

$$
\begin{aligned}
& \text { mjərə [DP [ec mə mašine-r } \mathrm{z}-\partial-\mathrm{q}_{\mathrm{w}} \text { əta--se]-r] јəwas } \\
& \text { Mira this car-ABS WH-ERG-break-PAST-ABS beat } \\
& \text { 'Mira beat the one/those who broke this car.' }
\end{aligned}
$$

Notice that the MC in (8) is almost identical to the MC in (4). The only difference is that (8) lacks a nominal head and has the ABS case marker $-r$ occur as a suffix on its predicate rather than on the nominal head.

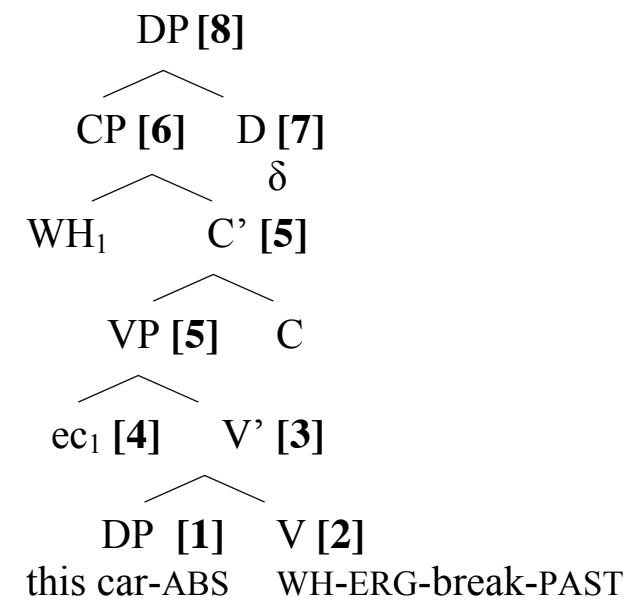

[1]-[6]. Same as the "headed relative" interpretation in (7): [1]-[6]

[7]. $\quad \delta \sim \lambda \mathrm{Q}[\mathrm{ly}[\mathrm{Q}(\mathrm{y})]]$ (same as in (7): [9])

[8]. $\quad \mathrm{DP} \sim \lambda \mathrm{Q}[\mathrm{ly}[\mathrm{Q}(\mathrm{y})]]\left(\lambda \mathrm{x}_{1} \cdot\left[\operatorname{break}(\mathrm{c})\left(\mathrm{x}_{1}\right)\right]\right)=\operatorname{ty}[\operatorname{break}(\mathrm{c})(\mathrm{y})]$

The syntactic structure and the complete semantic derivation for example in (8) are given in (9) above. Given the close similarity, we assume that both the licensing conditions for the operator and the trace/variable and the semantic 
derivation of a "free relative-like" MC are the same as those of a "headed relative-like" MC. The only difference is that the set of individuals the "free relative-like" MC ends up denoting does not intersect with the set denoted by the nominal head, since the latter is missing (or semantically inert). Maximalization applies directly to the set denoted by the $\mathrm{MC}$ and turns it into its maximal individual.

\section{3. "Embedded constituent interrogative" interpretation}

MCs can also occur as the complement of an interrogative predicate and be interpreted as embedded constituent interrogatives. Before examining this kind of MC more closely, let's briefly look at matrix constituent interrogatives in Adyghe first in order to better understand what is peculiar of MCs. Matrix constituent interrogatives in Adyghe are clefts. Consider the example in (10). The wh-word carries the question marker (Q) $-a$ as its suffix and occurs either sentence final (10a) or sentence initial (10b). The remainder of the sentence is identical to the "free relative-like" MC in (8) above.

 this car-ABS WH-ERG-break-PAST-ABS who-Q
b. xet-a [DP [CP who-Q this car-ABS WH-ERG-break-PAST-ABS
'Who broke this car?' (Lit. 'who is it that broke this car?')

Matrix constituent interrogatives cannot be embedded, regardless of the position of the wh-word, the presence of the $\mathrm{Q}$ marker, and the kind of case marker verbal suffix (11). Notice that the problem is not with the matrix predicate not taking a complement, since in Adyghe 'ask' can take a DP complement, to which it assigns oblique case (12).

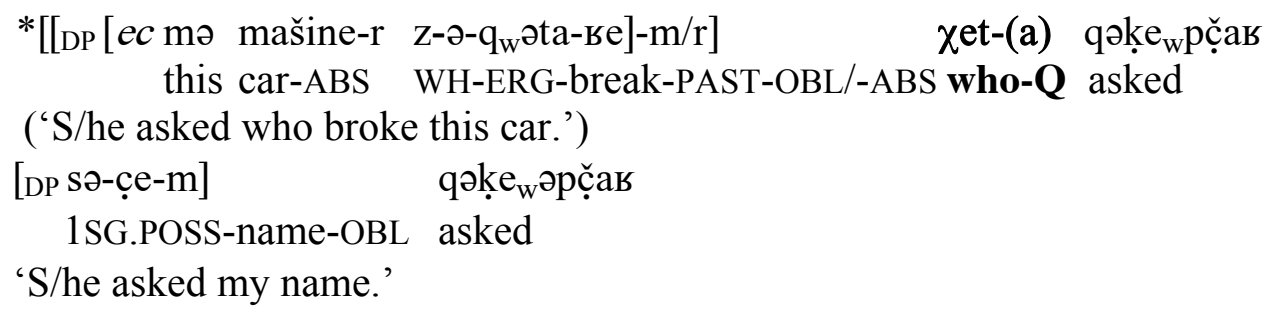

The meaning of an embedded constituent interrogative is expressed by means of an MC, instead. In (13), for instance, an MC occurs as the complement of the interrogative predicate 'ask' and is interpreted as denoting the set of propositions that constitute a possible answer to the question 'Who broke this car?' (following Hamblin 1973). 


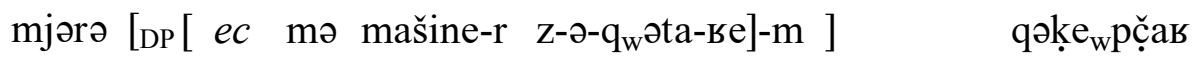
Mira this car-ABS WH-ERG-break-PAST-OBL asked 'Mira asked who/what broke this car.'

The "embedded-constituent-interrogative-like" MC in (13) is identical to the "free-relative-like" mystery clause in (8). If the same semantic derivation applies (which is the default hypothesis), the MC in (13) ends up denoting an individual, while the interrogative predicate is looking for a set of propositions, and a type mismatch arises. This mismatch is reminiscent of "concealed questions." Concealed questions are DPs (denoting individuals, names, or numerical values) that can occur as the complement of interrogative predicates and be interpreted as embedded interrogatives. For instance, the DP the capital of France denotes an individual (a certain city in France), but in the sentence Tell me [the capital of France] is interpreted as the bracketed embedded constituent interrogatives in Tell me [what the capital of France is]. Similarly, the DP the price denotes a certain numerical value (or an individual concept from worlds to numerical values); but it can also occur as the complement of the interrogative predicate ask as in She asked me [the price] and be interpreted in the same way as the bracketed embedded constituent interrogative in She asked me [what the price was]. Adyghe has true concealed questions too, as shown by the bracketed DPs in (14)-(15) and their interpretation.

$$
\text { [DP } \partial \text {-wase-r] } \quad \text { qa? }{ }_{w} \text { ə }
$$

3SG.POSS-price-ABS say.IMPERATIVE

'Say how much this costs.' (lit.: 'Say its price.')

[DP mə səxat-ər] sə-ŝer-ep

this hour-ABS 1SG-know-NEG

'I did not know what time it was.' (Lit.: 'I did not know the hour.')

$$
\begin{array}{ccc}
{\left[\begin{array}{ll}
\text { DP } & \gamma_{\mathrm{w}} ə \mathrm{~g}_{\mathrm{w}} \text { ə-r }
\end{array}\right]} & \text { qe-sə-a- }{ }_{\mathrm{w}} \text { əte ̌̌er-ep } \\
& \text { road-ABS } & \text { INV-1SG-3PL-retell-NEG }
\end{array}
$$

'They would not tell me how to get there.' (Lit.: '... tell me the road.')

We suggest that the very same mechanism that allows speakers to interpret certain DPs in the complement position of an interrogative predicate as embedded constituent interrogatives is at work when an MC occurs as the complement of the very same kind of predicate. The specific nature of that mechanism has been at the center of an ongoing debate, recently enriched with several contributions (Heim 1979; Frana 2006; Nathan 2006; Romero 2006; Caponigro and Heller 2007). 
(17) DP [10]

$\mathrm{Op}_{\mathrm{CQ}}$ [9] DP [8]

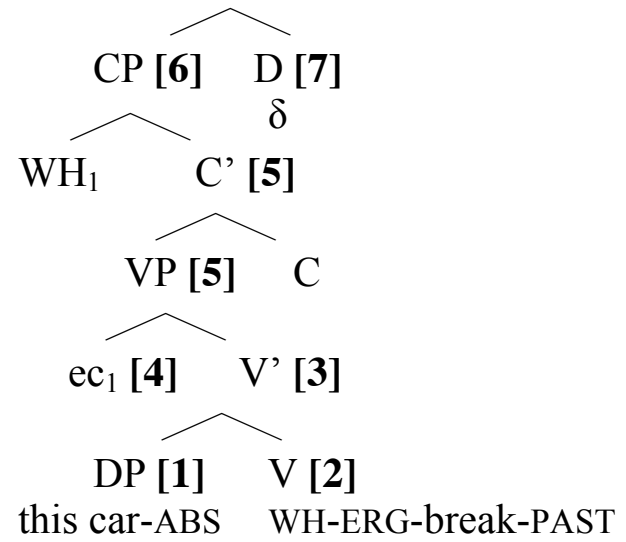

[1]-[7]. Same as the "free relative" interpretation in (9):[1]-[7]

[8]: $\quad \lambda \mathrm{w}_{1<\mathrm{s}>} . \mathrm{ly}\left[\operatorname{break}\left(\mathrm{w}_{1}\right)(\mathrm{c})(\mathrm{y})\right]$

[9]. $\quad$ Op $\mathrm{p}_{\mathrm{CQ}} \sim \lambda \mathrm{x}_{<\mathrm{se}>} \cdot \lambda \mathrm{p}_{<\mathrm{st}} .[\mathrm{y}[\mathrm{p}=\lambda \mathrm{w}[\mathrm{y}=\mathrm{x}(\mathrm{w})]]$

[10]. $\quad$ DP $\sim \lambda x \cdot \lambda p\left[\exists y[p=\lambda w[y=x(w)]]\left(\lambda w_{1} .1 y\left[\operatorname{break}\left(w_{1}\right)(c)(y)\right]\right)\right.$

$=\lambda \mathrm{p}[\exists \mathrm{y}[\mathrm{p}=\lambda \mathrm{w} \cdot[\mathrm{y}=\mathrm{ty}[\operatorname{break}(\mathrm{w})(\mathrm{c})(\mathrm{y})]]$

In the semantic derivation of the MC in (13) given in (17) above, we assume that the interrogative predicate licenses a Concealed Question operator (Op $\mathrm{p}_{\mathrm{CQ}}$ in [9]) that takes the intension of its complement (the individual concept in [8]) and returns an identity question, i.e. a set of propositions ([10]). The choice of $\mathrm{Op}_{\mathrm{CQ}}$ is just for sake of simplicity and presentational purposes. The semantic contribution of $\mathrm{Op}_{\mathrm{CQ}}$ could easily be incorporated in the lexical semantics of the interrogative predicate or other type-shifting operations could be postulated. We refer the interested reader to the work mentioned above for a detailed discussion of the data and the various proposals. As far as we can tell, any of those solutions would be compatible with our analysis.

It is known that the nature of the nominal within a DP plays a role in the availability of a concealed question interpretation for the DP. In particular, relational nominals can more easily trigger a concealed question interpretation than non-relational ones (see Nathan 2006, Romero 2006, and Caponigro and Heller 2007, a.o.). Also, Nathan (2006) notices that a relative clause can facilitate the concealed question interpretation of DPs containing a non-relational noun when it modifies it. For instance, compare (18a) and (18b) (Nathan 2006: 116, ex. 70a and 71a, respectively). 
a. \# Tell me [DP USNDH's semanticist].

b. Tell me [DP the semanticist who teaches at USNDH].

The main predicate of both sentences is tell, which selects for a proposition or a set of propositions in its complement position. In both cases, tell takes an individual denoting DP containing the non-relational noun semanticist as its complement. A concealed question interpretation of the DP complement is needed in order for the sentences to be acceptable. In (18a), semanticist is modified by the Saxon genitive USNDH'S and the sentence is judged awkward. In (18b), semanticist is modified by a relative clause with virtually the same semantic content as the Saxon genitive and the sentence is judged much better.

If Nathan's (2006) generalization is correct, it would support our proposal that a concealed question interpretation is always available with "embeddedconstituent-interrogative-like" MCs. In fact, these clauses always lack the potential obstacle to a concealed question interpretation, namely the wrong kind of nominal, since they do not have a nominal head at all. On the other hand, they always have what facilitates a concealed question interpretation, namely a relative clause, since they are relative clauses according to our analysis.

To sum up, although Adyghe has matrix interrogatives with wh-words and a question marker, it cannot embed them at all. On the other hand, it can use MCs, which lack both wh-words and the question marker, to convey what embedded constituent interrogatives convey in a language like English, i.e. a set of propositions.

\section{4. "Embedded declarative" and "embedded polar interrogative" interpretations}

Adyghe also uses an MC to convey what in English and in other languages would be conveyed by means of an embedded declarative or interrogative. Let's start by looking at the matrix counterparts to highlight the differences. (19) repeats the matrix declarative (1), while (20) gives the corresponding matrix polar interrogative. The only difference between the two is the already familiar interrogative suffix $-a(\mathrm{Q})$ on the predicate of the interrogative clause.

ç̣’ale-m mə mašine-r Ø-ə-q $q_{w}$ əta-s

boy-ERG this car-ABS 3SG.ABS-3SG.ERG-break-PAST.DECL

'The boy broke this car.'

(20) ִ̣’ale-m mə mašine-r $\quad$ - $\mathrm{q}_{\mathrm{w}}$ əta-ь-a

boy-ERG this car-ABS 3SG.ERG-break-PAST-Q

'Did the boy break this car?'

Neither the matrix declarative nor the matrix interrogative clause can be 
embedded, as shown in (21) and (22), respectively.
* [ ç̣’ale-m mə mašine-r ə-q $\mathrm{q}_{\mathrm{w}}$ əta-r $]$
sə-g $\mathrm{g}_{\mathrm{w}} \mathrm{pše}-\mathrm{s}$
boy-ERG this car-ABS 3SG.ERG-break-PAST 1SG-think-PAST

('I thought that the boy broke this car.')

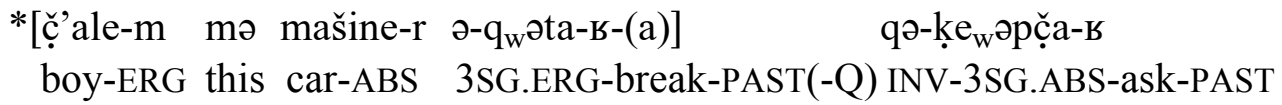
('S/he asked if the boy broke this car.')

Notice that both the propositional attitude predicate 'think' and the interrogative predicate 'ask' can take nominal complements in Adyghe, as shown by the object DPs in (23) and (24), respectively.

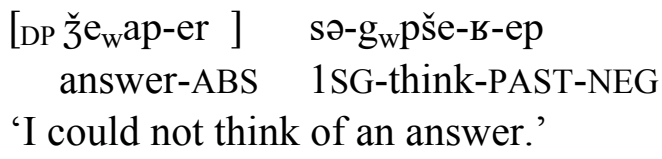

'I could not think of an answer.'

[DP sə-çe-m] qəḳe

1sg.poss-name-OBL asked

'She asked my name.'

MCs too can occur as the complement of 'think' or 'ask,' as shown in (25) and (26) respectively. Notice that the two MCs are identical, except for the case marker verbal suffix (in bold), which depends on the different case assigning properties of the main predicates.

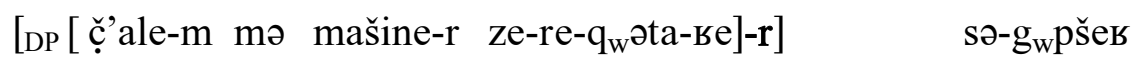
boy-ERG this car-ABS WH-APPL-break-PAST-ABS 1SG-thought 'I thought that the boy had broken this car.'

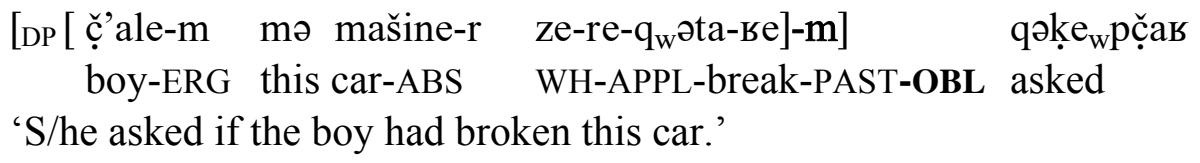

We assume that both bracketed clauses in (25) and (26) are MCs since they both exhibit a case marking suffix on their predicate and have the overt wh-agreement verbal prefix $z \boldsymbol{\theta}^{-}$, like the other MCs we have seen so far. Also, both kinds of MCs are strong syntactic islands. (27)-(29) show that the bolded constituents cannot scramble out of the MC, which is true for any constituent in the MC. This is in contrast to regular DPs, which are transparent (see Caponigro and Polinsky to appear for examples and discussion). 


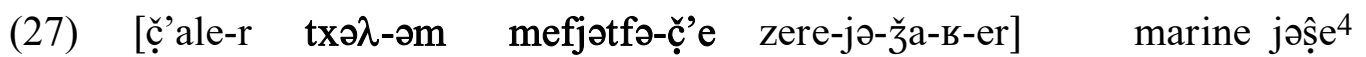
boy.ABS book-OBL 5_days-INSTR WH-3SG-read-PAST-ABS M knows ' arina knows that the boy read the book in five days.'

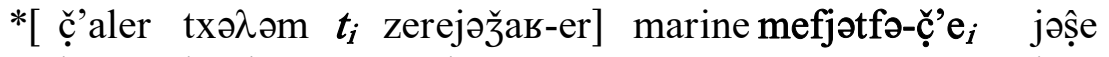

$$
\begin{aligned}
& \text { boy book read-ABS M 5_days-INSTR knows }
\end{aligned}
$$



$$
\begin{aligned}
& \text { book } M \text { boy 5_days-INSTR read-ABS knows }
\end{aligned}
$$

What distinguishes the MCs in (25) and (26) from the other MCs we have seen so far is the verbal prefix -re-, which looks like an applicative marker occurring higher on the verb than any other applicatives (see Caponigro and Polinsky to appear for a more detailed discussion). Despite all these similarities, (25) and (26) are interpreted rather differently. The MC in (25) is interpreted as an embedded declarative in English, that is, denoting the proposition 'that the boy had broken this car.' On the other hand, the MC in (26) semantically behaves like an embedded polar interrogatives in English and denotes a set containing the proposition 'that the boy had broken this car' and its negation 'that the boy had not broken this car' (Hamblin 1973).

We propose that the "embedded-declarative-like" MCs and "embeddedpolar-interrogative-like" MCs are identical syntactically and semantically. They are relative clauses that instantiate an operator-variable configuration, like all other MCs. The relative clause nature of these MCs would account for their wh-agreement prefix, their case marker verbal suffix, and the ban on extraction. Their variable, though, ranges over a different kind of semantic object, as signaled by the high applicative verbal prefix -re-, which distinguishes them from the other MCs. We suggest that the variable of these MCs ranges over polarity operators. A polarity operator is a function that takes a proposition $\mathrm{p}$ and returns either the very same proposition $p$ (positive polarity operator, $f_{P O S}: \lambda p . p$ ) or its negation $\sim p$ (negative polarity operator, $f_{\mathrm{NEG}}: \lambda p . \sim p$ ). Therefore, the whole MC ends up denoting a set containing the two polar operators $\left\{f_{\mathrm{POS}}, \mathrm{f}_{\mathrm{NEG}}\right\}$, after standard lambda abstraction over the variable has applied.

Polar operators and variables over them have been independently argued for to account for scope interactions within polar interrogatives in English and other languages (see Guerzoni 2004, Romero and Han 2004). The intuition that we want to capture by means of polar operators is that embedded declaratives and embedded polar interrogatives share a basic feature at the level of their semantic contribution: their denotations are built on the same proposition. For instance, the denotations of the embedded declarative (that) Mary left and of the embedded polar interrogative if/whether Mary left in English depend both on the proposition 'that Mary left'. This proposition is either the actual denotation of the clause, as in

\footnotetext{
${ }^{4}$ The embedded clause is based on an example from Arkadjev and Letuchiy (2008: ex. 22).
} 
the case of the embedded declarative, or the proposition that together with its negation occurs as a member of the set-denotation, as in the case of the embedded polar interrogative.

In English and similar languages, a complementizer system overtly distinguishes the two kinds of clauses and may be taken to be responsible for their difference in denotation. In Adyghe, there is no evidence for any declarative or interrogative complementizers (see Caponigro and Polinsky to appear for reasons why the prefix that we describe as a high applicative cannot be analyzed as a complementizer). More generally, there is no evidence for any morphological or structural difference between those two kinds of clauses. Also, when the matrix predicate is the Adyghe equivalent of a verb like 'know' that can take either a declarative or an interrogative clause as its complement, our consultants judge the $\mathrm{MC}$ ambiguous between a declarative and an interrogative (30).

$$
\begin{aligned}
& \text { [DP[CP marine məš' ze-re-š'ə-pse }{ }_{\mathrm{w}} \text { re]-r] aš } \quad \text { jə-ṣ̂er-ep } \\
& \text { Marina here WH-APPL-LOC-be-ABS 3SG.ERG 3SG-knows-NEG } \\
& \text { 'S/he does not know that/whether Marina lives here.' }
\end{aligned}
$$

Therefore, the difference in meaning between the MCs like (25) and (26) must be due to some other mechanism. One option is to make the lexical meaning of the matrix predicates responsible for the difference in meaning of the whole sentence. Both propositional attitude and interrogative predicates would select for a set of polarity operators in Adyghe, but they would impose different truth-conditions with respect to that set (and the other arguments they select for). This option is rather stipulative however.

We would like to suggest an alternative approach that reduces these two kinds of MCs to another construction that is found in Adyghe. (31) shows a familiar "embedded-declarative-like" MC. (32) and (33) show a construction that our consultants judge truth-conditionally equivalent to (31), although it is structurally slightly different. (32) and (33) contain what looks like the "embedded-declarative-like" MC in (31) except that now the MC is immediately followed by a nominal head meaning 'news' or 'validity/verity/truth' (in bold in the examples below) which hosts the case marker suffix. ${ }^{5}$

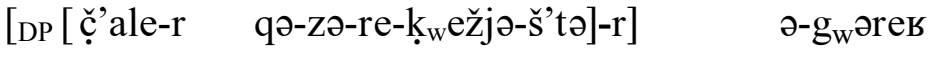

$$
\begin{aligned}
& \text { boy-ABS INV-WH-APPL-return-FUT-ABS 3SG-understood } \\
& \text { 'S/he understood that the boy will arrive.' }
\end{aligned}
$$

\footnotetext{
${ }^{5}$ Gerasimov and Lander (2008) make a similar observation. However, their semantic analysis is different from ours. They suggest, following the ideas in Nichols (2003), that such MCs denote 'facts'. Unlike ours, this proposal cannot be easily extended to those MCs that are interpreted as embedded polar interrogatives, despite their morphosyntactic identity.
} 
[DP [ç̣’ale-r qə-zə-re-ḳwežjə-š’tə] qeba-r] $\quad$ - g $_{\mathrm{w}}$ əreь boy-ABS INV-WH-APPL-return-FUT news-ABS 3SG-understood 'S/he understood that the boy will arrive.'

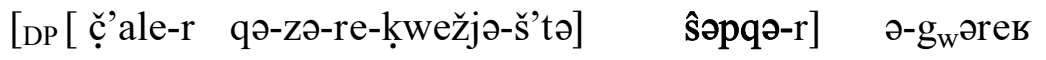

$$
\begin{aligned}
& \text { boy-ABS INV-WH-APPL-return-FUT verity-ABS 3SG-understood } \\
& \text { 'S/he understood that the boy will arrive.' }
\end{aligned}
$$

The construction in (32) and (33) may look similar to the construction "the fact/claim/rumor that ..." in English. These English clauses, however, do not always have the same distribution as nor are truth-conditionally equivalent to their counterparts without the nominal (e.g. She remembers/*thought the (fact/claim/rumor) that it was sunny). On the other hand, we have not found any distributional or interpretative differences between the MC in (31) and the bracketed DP in (32) or (33). Our hypothesis is that, in Adyghe, (i) nominals like the bolded one in (32) or (33) are responsible for turning a set of polarity operators into a proposition; (ii) when not overt like in (31), a silent version of these nominals occurs with the same semantic contribution.

(34) shows the detailed semantic derivation of the MC in (25). As before, we assume that the VP ends up denoting a proposition $\mathrm{p}_{0}$ ([5]) and the wh-operator $(\mathrm{WH})$ is in Spec of $\mathrm{CP}$. This time the operator binds an empty category in the specifier of an applicative projection (ApplP), which introduces the variable ranging over polarity operators ([7]). The operator WH triggers lambda abstraction over the coindexed gap/variable and returns a function from polarity operators to propositions, as the meaning of the $\mathrm{CP}$ ([10]). The silent nominal ([11]) is defined as a complex function taking a function $\mathrm{F}$ from polarity operators to propositions as its argument and returning just the proposition that constitutes the value of the positive polarity operator. The combination of the silent nominal with the $\mathrm{CP}$ returns the proposition $\mathrm{p}_{0}$ we started with as the denotation of VP ([12]). A proposition is the correct semantic object for a propositional attitude predicate like 'think'. Therefore type-shifting needs not to apply, the head D is semantically inert, and the whole complex DP inherits the same denotation as the NP, that is, the proposition $\mathrm{p}_{0}$ ([13]). 


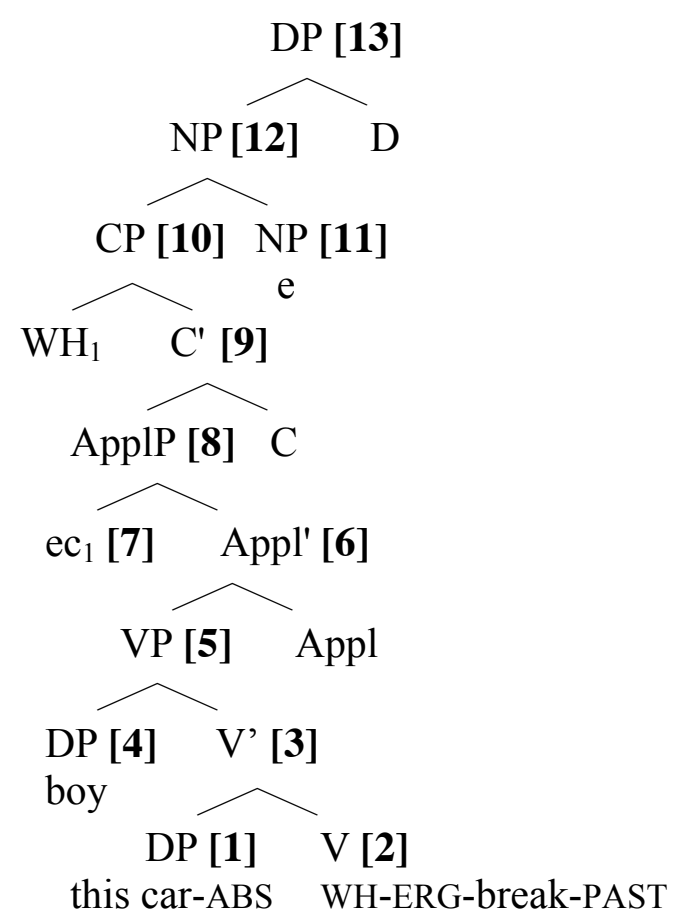

[1]. [DP this car-ABS] $\sim>\mathrm{c}_{<\mathrm{e}>}$ (constant)

[2]. [v WH.ERG-break-PAST] $>\lambda y \cdot \lambda x \cdot \lambda w \cdot b r e a k(w)(y)(x)$

[3]. $\quad \mathrm{V}^{\prime} \sim>\lambda \mathrm{x} . \lambda \mathrm{w} \cdot \operatorname{break}(\mathrm{w})(\mathrm{c})(\mathrm{x})$

[4]. [DP the boy] $\sim>\mathrm{b}_{<\mathrm{e}>}$ (constant)

[5]. $\quad \mathrm{VP} \sim \lambda \mathrm{w} \cdot \operatorname{break}(\mathrm{w})(\mathrm{c})(\mathrm{b})=_{\operatorname{def}} \mathrm{p}_{0}$

[6]. Appl' $\sim>\mathrm{p}_{0}$ (same as [5])

[7]. $\quad \mathrm{ec}_{1} \sim>\mathrm{f}_{\mathrm{X}<\mathrm{st}, \mathrm{s} \triangleright}$ (range of variable $f_{X}:\left\{\mathrm{f}_{\mathrm{POS}} \lambda \lambda \mathrm{p} . \mathrm{p}, \mathrm{f}_{\mathrm{NEG}}: \lambda \mathrm{p} . \sim \mathrm{p}\right\}$ )

[8]. ApplP $\sim \mathrm{f}_{\mathrm{X}}\left(\mathrm{p}_{0}\right)$

[9]. $\quad \mathrm{C}^{\prime} \sim>\mathrm{f}_{\mathrm{X}}\left(\mathrm{p}_{0}\right)$ (same as [8])

[10]. [CP $\left.\mathrm{WH}_{1} \mathrm{C}^{\prime}\right] \sim \lambda \mathrm{f}_{\mathrm{X}} \cdot \mathrm{f}_{\mathrm{X}}\left(\mathrm{p}_{0}\right)$

[11]. [NP $\mathrm{e}] \sim \lambda \mathrm{F}_{<<\mathrm{st}, \mathrm{st}>\mathrm{s} \downarrow} \cdot \mathrm{F}\left(\lambda \mathrm{p}_{<\mathrm{st} \triangleright} . \mathrm{p}\right)$ (equivalently, $\lambda \mathrm{F} . \mathrm{F}\left[\mathrm{f}_{\mathrm{POS}}\right]$ )

[12]. [NP CP e] $\sim \lambda \mathrm{F} . \mathrm{F}(\lambda \mathrm{p} . \mathrm{p})\left(\lambda \mathrm{f}_{\mathrm{X}} . \mathrm{f}_{\mathrm{X}}\left(\mathrm{p}_{0}\right)\right)=\mathrm{p}_{0}$

[13]. [DP NP D] $\sim \mathrm{p}_{0}$ (same as [12])

The very same nominals that can introduce MCs that are interpreted as embedded declarative in (32) and (33) can introduce MCs that are interpreted as embedded polar interrogatives as well. (35) shows a familiar MC, while (36) shows the corresponding construction with one of those special nominals. Our consultants judge them truth conditionally equivalent.

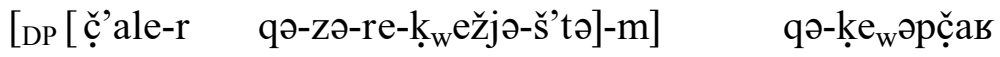

$$
\begin{aligned}
& \text { boy-ABS INV-WH-APPL-return-FUT-OBL INV.3SG-asked } \\
& \text { 'S/he asked if the boy will arrive.' }
\end{aligned}
$$



boy-ABS INV-WH-APPL-return-FUT verity-OBL INV.3SG-asked 'S/he asked if the boy will arrive.'

We suggest that the syntax of embedded polar interrogative-like MCs is identical to the one of embedded-declarative-like MCs, and their semantics is very similar too. The only difference is in the meaning of the (silent) nominals. Let's illustrate it with an example. The syntactic tree for the embeddedpolarity-interrogative-like MC in (20) is identical to that of the embeddeddeclarative-like in (34). Therefore, in (37) we just give the part of the tree that is relevant to show the semantic differences. The CP in [10] in (37) denotes the same function as in [10] in (34) above. The silent nominal in [11] now denotes a complex function taking a function $\mathrm{F}$ from polarity operators to propositions as its argument and returning the set containing the two propositions that constitute the values of the positive and negative polarity operators, respectively. The combination of the silent nominal with the CP returns the set $\left\{\mathrm{p}_{0}, \sim \mathrm{p}_{0}\right\}$ containing the values of both the positive and the negative operators when applied to $\mathrm{p}_{0}([12])$. A set of propositions is the correct semantic object for the complement of an interrogative predicate like 'ask', therefore no type-shifting is needed, D is semantically inert, and the whole complex DP inherits the same denotation as the NP, that is, the set $\left\{\mathrm{p}_{0}, \sim \mathrm{p}_{0}\right\}$ ([13]).

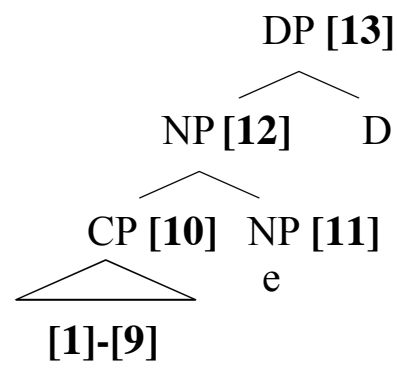

[1]-[9]. Same as the "embedded declarative" interpretation in (34):[1]-[9]

[10]. $\quad \mathrm{CP} \sim \lambda \mathrm{f}_{\mathrm{X}} \cdot \mathrm{f}_{\mathrm{X}}\left(\mathrm{p}_{0}\right)$

[11]. $\quad[\mathrm{NP} \mathrm{e}] \sim \lambda \mathrm{F}_{<<\mathrm{st}, \mathrm{st}>\mathrm{st}>} \cdot \lambda \mathrm{q}_{<\mathrm{st}>}[\mathrm{F}(\lambda \mathrm{p} . \mathrm{p})=\mathrm{q} \vee \mathrm{F}(\lambda \mathrm{p} . \sim \mathrm{p})=\mathrm{q}]$ (equivalently, $\left.\lambda \mathrm{F} . \lambda \mathrm{q}\left[\mathrm{F}\left(\mathrm{f}_{\mathrm{POS}}\right)=\mathrm{q} \vee \mathrm{F}\left(\mathrm{f}_{\mathrm{NEG}}\right)=\mathrm{q}\right]\right)$

[12]. $\quad\left[\mathrm{NP} C \mathrm{CP}\right.$ e] $\sim \lambda \mathrm{F} . \lambda \mathrm{q}[\mathrm{F}(\lambda \mathrm{p} . \mathrm{p})=\mathrm{q} \vee \mathrm{F}(\lambda \mathrm{p} . \sim \mathrm{p})=\mathrm{q}]\left(\lambda \mathrm{f}_{\mathrm{X}} \cdot \mathrm{f}_{\mathrm{X}}\left(\mathrm{p}_{0}\right)\right)$

$=\lambda \mathrm{q} \cdot\left[\mathrm{p}_{0}=\mathrm{q} \vee \sim \mathrm{p}_{0}=\mathrm{q}\right]$

[13]. $\quad\left[\right.$ DP NP D] $\sim \lambda \mathrm{q}\left[\mathrm{p}_{0}=\mathrm{q} \vee \sim \mathrm{p}_{0}=\mathrm{q}\right]$ (same as [12])

\section{Conclusions}

In Caponigro and Polinsky (to appear) we argue that MCs in Adyghe are all complex DPs containing relative clauses, thus instantiations of a syntactic 
configuration in which an operator binds (i.e. c-commands and is coindexed with) an empty category. In this paper, we have shown how the five different interpretations that $\mathrm{MCs}$ can receive can be derived from the same basic syntactic structure and the differences in verbal morphology and/or the environment they occur in.

If our proposal is on the right track, Adyghe only makes use of the relativization strategy to express what the more familiar languages express by means of relativization or clausal complementation. Thus, "clausal complements" are not an indispensable part of grammar; they can be fully represented by relative clauses within complex DPs. What follows from this simplicity is that the more familiar complementation strategies, ones that we normally take for granted, may not constitute a structural necessity in natural language.

\section{References}

Arkadjev, Peter and Alexander Letuchiy: 2008, 'Derivacii antipassivnoj zony v adygejskom jazyke,' V. Plungyan and S. Tatevosov (eds) Issledovanija po teorii grammatiki, 4: Issledovanija po glagol'noj derivacii, 121-137, Jazyki russkoj kul'tury, Moscow.

Caponigro, Ivano: 2004, 'The Semantic Contribution of wh-Words and Type Shifts: Evidence from Free Relatives Cross-linguistically,' in R. Young (ed.) Proceedings of SALT XIV, 38-55, CLC Publications, Cornell University, Ithaca.

Caponigro, Ivano and Daphna Heller: 2007, 'The Non Concealed Nature of Free Relatives: Implications for Connectivity Crosslinguistically,' in C. Barker and P. Jacobson (eds) Direct Compositionality, pp. 37-263, Oxford University Press, Oxford, UK.

Caponigro, Ivano, and Maria Polinsky: to appear, 'Relatively Speaking (in Circassian),' Proceedings of WCCFL XXVII.

Chierchia, Gennaro: 1998, 'Reference to Kinds across Languages,' Natural Language Semantics 6, 339-405.

Colarusso, John: 1992. A Grammar of the Kabardian Language, University of Calgary Press, Calgary.

Dayal, Veneeta: 2004, 'Number Marking and (In)definiteness in Kind Terms,' Linguistics and Philosophy 27, 393-450.

Frana, Ilaria: 2006, 'The de re Analysis of Concealed Questions. A Unified Approach to Definite and Indefinite Concealed Questions,' in C. Tancredi, M. Kanazawa, I. Imani, and K. Kusumoto (eds) Proceedings of SALT XVI. (http://research.nii.ac.jp/salt16/proceedings.html)

Gerasimov, Dmitry, and Yuri Lander: 2008, 'Reljativizacija pod maskoj nominalizacii i faktivnyj argument $\mathrm{v}$ adygejskom jazyke,' in V. Plungyan and S. Tatevosov (eds) Issledovanija po teorii grammatiki, 4: Issledovanija po glagol'noj derivacii, 290-313, Jazyki russkoj kul'tury, Moscow. 
Groenendijk, Jeron and Martin Stokhof: 1984, Studies on the Semantics of Questions and the Pragmatics of Answers. Doctoral Dissertation, University of Amsterdam.

Guerzoni, Elena: 2004, 'Even NPIs in Yes-No Questions,' Natural Language Semantics 12, 319-343.

Hamblin, Charles L.: 1973, 'Questions in Montague English,' Foundations of Language 10, 41-53.

Heim, Irene: 1979, 'Concealed Questions,' in R. Bäuerle, U. Egli, A. von Stechow (eds) Semantics from different points of view, 51-60, Springer, Berlin.

Jacobson, Pauline: 1995, 'On the Quantificational Force of English Free Relatives,' in. E. Bach, E. Jelinek, A. Kratzer, B. Partee (eds) Quantification in Natural Language, 451-486, Kluwer, Dorderecht.

Karttunen, Lauri: 1977, 'Syntax and semantics of questions,' Linguistics and Philosophy 1, 3-44.

Montague, Richard: 1973, 'The Proper Treatment of Quantification in English,' in K.J.J Hintikka, J.M.E. Moravcsik, and P. Suppes (eds) Approaches to Natural Language, 221-242, Reidel, Dordrecht.

Nathan, Lance. 2006. On the interpretation of concealed questions. Doctoral dissertation, MIT.

Nichols, Lynn: 2003, 'Attitude Evaluation in Complex NPs,' in A. Carnie, H. Harley, and M.A. Willie (eds) Formal Approaches to Function in Grammar, 155-164, Benjamins, Amsterdam.

O’Herin, Brian: 2001, 'Abaza Applicatives,' Language 77, 477-493.

O'Herin, Brian: 2002, Case and Agreement in Abaza, SIL International, Dallas.

Partee, Barbara H.: 1986, 'Noun Phrase Interpretation and Type-shifting Principles,' in J. Groenendijk, D. de Jongh, and M. Stokhof (eds) Studies in Discourse Representation Theory and the Theory of Generalized Quantifiers, 115-143, Foris, Dordrecht.

Quine, Willard V.O.: 1960, Word and object, The MIT Press, Boston.

Rizzi, Luigi: 1990, Relativized Minimality, The MIT Press, Boston.

Rogava, Georgij, and Zejnab Keraševa: 1966, Grammatika adygejskogo jazyka, Krasnodarskoe knižnoe izdatel'stvo, Majkop.

Romero, Maribel: 2006, 'On Concealed Questions,' in C. Tancredi, M.

Kanazawa, I. Imani, and K. Kusumoto (eds) Proceedings of SALT XVI. (http://research.nii.ac.jp/salt16/proceedings.html)

Romero, Maribel and Chung-hye Han: 2004, 'On Negative Yes/No Questions,' Linguistics \& Philosophy 27, 609-658.

Smeets, Rijks: 1984, Studies in West Circassian Phonology and Morphology, Leiden University Press, Leiden. 